\title{
Urgences
}

\section{Un coin perdu}

\section{Yves Vaillancourt}

\section{Numéro 11, 3e trimestre 1984}

URI : https://id.erudit.org/iderudit/025173ar

DOI : https://doi.org/10.7202/025173ar

Aller au sommaire du numéro

Éditeur(s)

Urgences

ISSN

0226-9554 (imprimé)

1927-3924 (numérique)

Découvrir la revue

Citer ce document

Vaillancourt, Y. (1984). Un coin perdu. Urgences, (11), 53-56.

https://doi.org/10.7202/025173ar

Ce document est protégé par la loi sur le droit d'auteur. L'utilisation des services d'Érudit (y compris la reproduction) est assujettie à sa politique d'utilisation que vous pouvez consulter en ligne.

https://apropos.erudit.org/fr/usagers/politique-dutilisation/
Cet article est diffusé et préservé par Érudit.

Érudit est un consortium interuniversitaire sans but lucratif composé de l'Université de Montréal, l'Université Laval et l'Université du Québec à Montréal. Il a pour mission la promotion et la valorisation de la recherche. https://www.erudit.org/fr/ 
YVES VAILLANCOURT

\section{Un coin perdu}




\section{UN COIN PERDU}

Étant donné que j'habite dans le quartier depuis quelque temps, il m'arrive souvent d'aller faire un tour par là. Je ne me lasse pas de parcourir le chemin qui me mène de mon appartement jusqu'à ce coin perdu où logeait mon ami B., il y a deux ans de cela.

Par ici ce n'est pas très gai. Arrivé au coin des rues Pratt et Glendale, dans cette obscure partie d'Outremont, si on regarde droit devant soi s'offre alors à la vue un vaste champ de ville d'où surgira peut-être un train. Autrefois, ce train me désolait, maintenant il me laisse plus ou moins indifférent quoiqu'il lui arrive encore de me plonger dans une morne rêverie faite de terrains vagues et de chiches dépotoirs de vieille tôle.

Chaque fois que je débouche sur cette petite rue Glendale, je reconstitue la trame de la vie de $B$. ces dernières années. Ce triste quartier, sans café ni discothèque, habité par des juifs invisibles protégeant une vieille petite école non moins invisible, fut pour lui une véritable retraite. C'était l'accalmie suivant les désordres du Carré St-Louis.

Quand je revins de mon exil sur la Côte-Nord, c'était en mars il y a deux ans, j'arrivai là avec deux valises. II faisait très froid, sur la porte il y avait une petite note: "Je reviens dans quinze minutes, B." Je passai ici trois semaines, juste le temps de préparer mon départ. Le soir, nous allions au bar de l'université et on s'en retournait toujours un peu saouls, parlant de livres et de filles. On entrait chez lui sans faire de bruit - ce qui malheureusement ratait à tout coup - pour ne pas réveiller la dame propriétaire. Une fois rendus en bas, le sous-sol nous apparaissait dans sa terrible qualité de sous-sol, c'est-à-dire terriblement bas de plafond.

Dans ce petit univers de solitaire, et ce autant dans la cuisine et la salle de bains jonchées de livres que dans la petite pièce où il avait son lit, B. disposait de fenêtres par lesquelles, je $\mathrm{m}$ 'en rendis compte à la troisième semaine, je ne voyais que 
trouble. Je partis donc.

De là-bas, c'est surtout de cette nuit que je me souviens. II $s^{\prime}$ agit de cette nuit quand je quittai Madrid et Maria et m'en fut à Grenade. J'étais seul dans mon compartiment, adossé à la fenêtre, les yeux rivés sur une minuscule lueur rose au-dessus de ma tête, et je m'endormis. II m'a semblé que le rêve que je fis était une représentation assez exacte de ce que l'état de veille m'aurait laissé libre de faire: contempler la campagne dénudée de Castille, si aride, et celle, déjà plus hospitalière, d'Andalousie. Au rythme d'une guitare, notre petit train s'en allait cahin-caha de par plaines et collines autrefois repaires de brigands. Au loin se profilait la Sierra Nevada derrière laquelle le soleil s'apprêtait à déverser sa lumineuse rosée.

Sifflet, arrêt, réveil, le village apparait, vieilles masures dans la campagne profonde. De ma fenêtre, je cherche ce vieux témoin d'humanité qu'est le paysan andalou qui sur le quai empoigne ses valises pour monter indolemment le marchepied.

"Eh sir, do you know where is Bates street?" Deux petits juifs qui se rendent bien compte que je tombe de la lune s'étonnent alors de me voir leur indiquer leur chemin. Je pointe du doigt pour mieux les orienter dans ce coin perdu, mais déjà le train s'en vient et efface mes paroles. 


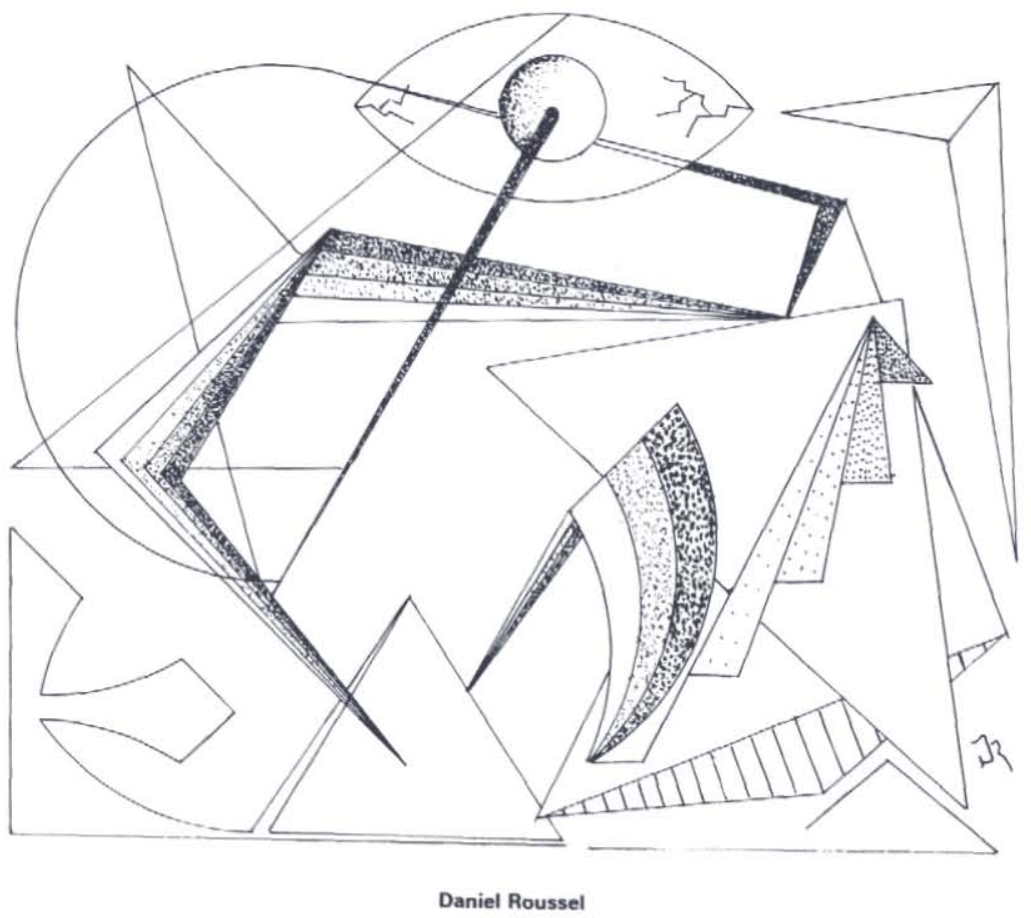

